\title{
Arterial Repair 4 Months After Zotarolimus-Eluting Stent Implantation Observed on Angioscopy
}

\author{
Takayuki Ishihara, MD; Masaki Awata, MD, PhD; Fusako Sera, MD; \\ Masashi Fujita, MD, PhD; Tetsuya Watanabe, MD, PhD; Osamu Iida, MD; \\ Yoshio Ishida, MD, PhD; Shinsuke Nanto, MD, PhD; Masaaki Uematsu, MD, PhD
}

\begin{abstract}
Background: Arterial repair in the early phase following implantation of a zotarolimus-eluting stent (ZES) remains unknown.

Methods and Results: Following implantation of 49 Endeavor ZES in 33 patients, follow-up angioscopy was performed in 13 patients (26 ZES) in the early phase (EP; $123 \pm 24$ days) and in 20 patients (23 ZES) in the middle phase (MP; $247 \pm 17$ days). Neointimal coverage (NIC) was graded as follows: grade 0 , stent struts exposed; grade 1, struts bulging into the lumen, although covered; grade 2, struts were embedded by the neointima but were seen translucently; grade 3, struts fully embedded and invisible. NIC was defined as heterogeneous for NIC grade variation $\geq 1$. The presence of thrombus and yellow plaque was also investigated. Although NIC heterogeneity tended to be more frequent in EP than in MP $(50 \%$ vs. $22 \%, P=0.070)$, and yellow plaque significantly more frequent $(58 \%$ vs. $13 \%$, $\mathrm{P}=0.0025)$, the majority of stents were dominant NIC grade 3 at both follow-up periods $(73 \%$ in EP vs. $78 \%$ in $M P$, $\mathrm{P}=0.75$ ). There was no significant difference in thrombus ( $23 \%$ in EP vs. $4 \%$ in MP, $P=0.10$ ) between the follow-ups.
\end{abstract}

Conclusions: Sufficient arterial repair may have occurred by 4 months after ZES implantation. (Circ J 2013; 77: 1186-1192)

Key Words: Angioscopy; Drug-eluting stent; Imaging; Zotarolimus-eluting stent

D rug-eluting stents (DES) have successfully decreased the rate of in-stent restenosis and target lesion revascularization by inhibiting neointimal proliferation. ${ }^{1}$ Late stent thrombosis (LST), however, can occur $>1$ month after DES implantation, causing sudden death or myocardial infarction. ${ }^{2,3}$ The American College of Cardiology Foundation/American Heart Association/Society for Cardiovascular Angiography and Interventions guideline recommends that dual anti-platelet therapy (DAPT) be continued for at least 1 year to avoid LST. ${ }^{4}$ Recently, new-generation DES have been developed to overcome the weaknesses of the first-generation DES, but there is as yet insufficient evidence to revise the guideline. Among the new-generation DES, zotarolimus-eluting stents (ZES; Endeavor, Medtronic, Minneapolis, MN, USA) have higher late lumen loss than other DES, ${ }^{5,6}$ suggesting that arterial repair occurs earlier with ZES than other DES. The arterial repair in the early phase following ZES implantation, however, remains unclear.

Angioscopy directly visualizes arterial healing following stenting. ${ }^{7-23}$ In our previous study, ZES had adequate neointimal coverage (NIC) on angioscopy at 8 months after stent implantation. ${ }^{9}$ In the present study, we used angiography to examine the earlier phase of arterial repair following ZES implantation.

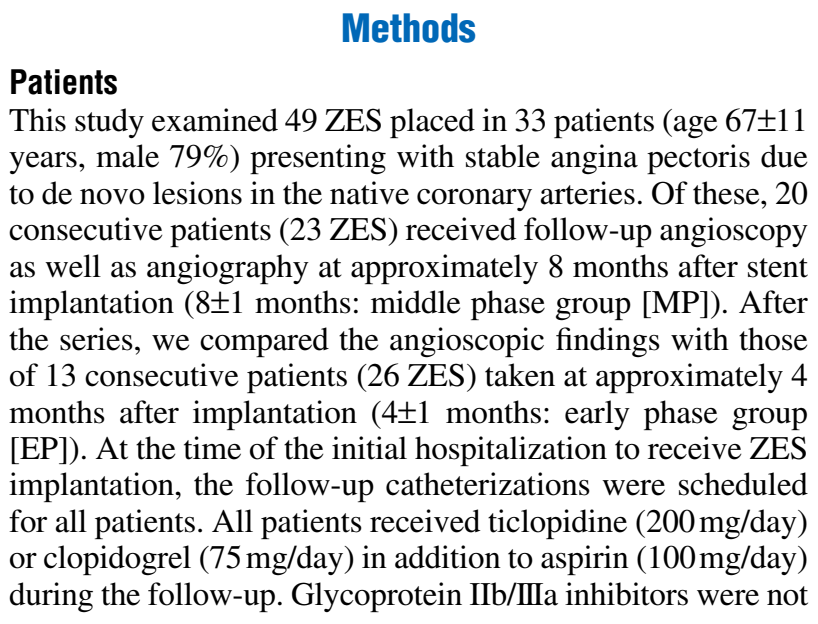

Received November 6, 2012; revised manuscript received December 17, 2012; accepted January 16, 2013; released online February 15, 2013 Time for primary review: 13 days

Kansai Rosai Hospital Cardiovascular Center, Amagasaki (T.I., M.A., F.S., M.F., T.W., O.I., Y.I., M.U.); Advanced Cardiovascular Therapeutics, Osaka University Graduate School of Medicine, Suita (S.N.), Japan

Mailing address: Masaki Awata, MD, PhD, Kansai Rosai Hospital Cardiovascular Center, 3-1-69 Inabaso, Amagasaki 660-8511, Japan. E-mail: masaki.awata@gmail.com

ISSN-1346-9843 doi:10.1253/circj.CJ-12-1369

All rights are reserved to the Japanese Circulation Society. For permissions, please e-mail: cj@j-circ.or.jp 


\begin{tabular}{lccc|}
\hline Table 1. Patient Characteristics & Early phase & Middle phase & P-value \\
No. patients & 13 & 20 & \\
Male & $10(77)$ & $16(80)$ & 1.0 \\
Age (years) & $68 \pm 13(72)$ & $66 \pm 10(66.5)$ & 0.43 \\
Old myocardial infarction & $5(38)$ & $6(30)$ & 0.71 \\
Coronary risk factors & & & \\
$\quad$ Hypertension† & $11(85)$ & $17(85)$ & 1.0 \\
Dyslipidemia & $7(54)$ & $14(70)$ & 0.47 \\
$\quad$ Diabetes mellitus§ & $5(38)$ & $8(40)$ & 1.0 \\
$\quad$ Current smoking & $2(15)$ & $10(50)$ & 0.067 \\
\hline
\end{tabular}

Data given as mean \pm SD (median) or $\mathrm{n}(\%)$. 'Receiving antihypertensive medication, systolic blood pressure $\geq 140 \mathrm{mmHg}$, or diastolic blood pressure $\geq 90 \mathrm{mmHg}$. $¥$ Oral agent or insulin treatment or $\mathrm{HbA} 1 \mathrm{c} \geq 6.5 \%$. $\$$ Treatment with medication, total cholesterol $\geq 220 \mathrm{mg} / \mathrm{dl}$, low-density lipoprotein cholesterol $\geq 140 \mathrm{mg} / \mathrm{dl}$, high-density lipoprotein cholesterol $\leq 40 \mathrm{mg} / \mathrm{dl}$, or triglycerides $\geq 150 \mathrm{mg} / \mathrm{dl}$.

\begin{tabular}{|lccc|}
\hline \multicolumn{2}{l}{ Table 2. Lesion and Procedure Characteristics } & & \\
No. lesions & Early phase & Middle phase & P-value \\
Target vessel & 23 & 22 & \\
$\quad$ LAD & & & 0.036 \\
LCX & $8(35)$ & $4(18)$ & \\
RCA & $8(35)$ & $3(14)$ & \\
Type B2/C lesions ${ }^{\dagger}$ & $7(30)$ & $15(68)$ & 1.0 \\
Chronic total occlusion & $12(52)$ & $12(55)$ & 1.0 \\
No. stents & $3(13)$ & $3(14)$ & \\
Stent diameter (mm) & 26 & 23 & 0.39 \\
Stent length (mm) & $3.1 \pm 0.4(3.0)$ & $3.2 \pm 0.3(3.0)$ & 0.26 \\
Stent implantation pressure (atm) & $20 \pm 7(18)$ & $22 \pm 5(18)$ & 0.17 \\
No. stents per lesion & $10 \pm 3(9)$ & $11 \pm 3(9)$ & 0.32 \\
\hline
\end{tabular}

Data given as mean \pm SD (median) or $n(\%)$. LAD, left anterior descending artery; LCX, left circumflex artery; RCA,

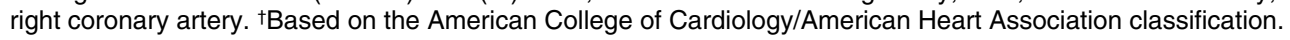

used because they are not approved for stable angina pectoris in Japan. The Medical Ethics Committee of Kansai Rosai Hospital approved the study, and all patients provided written informed consent.

\section{Angiographic and Angioscopic Follow-up}

Coronary angiography (CAG) was performed after unfractionated heparin $(5,000 \mathrm{IU})$ was given into the radial or femoral artery via the inserted sheath, and isosorbide dinitrate $(2.5 \mathrm{mg})$ into the coronary artery. Angioscopy was subsequently performed using a Vecmova NEO angioscope catheter (FiberTech, Tokyo, Japan), the detailed specifications and usage of which have been described elsewhere. ${ }^{7,10}$ Briefly, the optical fiber was placed at the distal segment of the coronary artery and was manually pulled back from the distal edge of the stent to the proximal edge under careful angioscopic and angiographic guidance. Angioscopic images consisted of 3,000 pixels with full color and were stored on digital videotape for off-line analysis.

\section{Quantitative CAG (QCA)}

CAG was performed in at least 10 projections, and the view showing the most severe stenosis was selected for QCA. ${ }^{24}$ QCA was then performed using a computerized angiographic analysis system (Pie Medical BV, Maastricht, the Netherlands) at the same angle of projection before stenting, immediately after stenting, and at follow-up.

\section{Angioscopy}

Angioscopy images were analyzed to determine the following: (1) dominant degree of NIC over the stent; (2) heterogeneity of NIC; (3) existence and extent of exposed struts; (4) existence of thrombus; and (5) existence of yellow plaque (YP) underneath the stent. NIC over the stent was classified into 4 grades as previously described:9,11-13,21 grade 0 , stent struts fully visible, similar to immediately after implantation; grade 1 , stent struts bulged into the lumen and, although covered, were still transparently visible; grade 2 , stent struts were embedded by the neointima but were seen translucently; grade 3 , stent struts fully embedded and invisible on angioscopy. Heterogeneity of NIC was defined as in our previous study. ${ }^{13,21}$ NIC was evaluated in the entire stented segments, and NIC was judged as heterogeneous when one or more differences in NIC grade were apparent. Struts that crossed the side branch were excluded from grading. The stent edges were also excluded from the heterogeneity analysis. Overlapping stent segments were evaluated separately. Existence and extent of the exposed struts were scored as follows: exposure (exp) 0 , no NIC grade 0 ; exp 1 , NIC grade 0 in limited areas; exp 2 , NIC grade $0<30 \%$ of stent surface area; exp 3, NIC grade $0 \geq 30 \%$, but not completely exposed; exp 4, struts completely exposed. Thrombus was defined based on the criteria adopted by the European Working Group on Coronary Angioscopy. ${ }^{14}$ The angioscopic definition of YP was adopted from earlier reports. $7,10,15,19,20$ 


\begin{tabular}{|lccc}
\hline \multicolumn{2}{l}{ Table 3. Quantitative Coronary Angiography } & & \\
Before intervention & Early phase & Middle phase & P-value \\
$\quad$ Minimal lumen diameter (mm) & $0.75 \pm 0.47(0.78)$ & $0.72 \pm 0.41(0.79)$ & 0.75 \\
Lesion length (mm) & $14 \pm 7(11.49)$ & $14 \pm 8(16.32)$ & 0.91 \\
Diameter stenosis (\%) & $73 \pm 16(70)$ & $76 \pm 13(74.5)$ & 0.23 \\
Reference diameter (\%) & $2.9 \pm 0.5(2.86)$ & $3.1 \pm 0.8(2.93)$ & 0.44 \\
After intervention & & & \\
$\quad$ Minimal lumen diameter (mm) & $2.7 \pm 0.4(2.625)$ & $2.9 \pm 0.5(2.91)$ & 0.062 \\
Diameter stenosis (\%) & $16 \pm 8(14.5)$ & $14 \pm 8(14)$ & 0.42 \\
Follow-up & & & \\
$\quad$ Minimal lumen diameter (mm) & $2.1 \pm 0.4(2.17)$ & $2.3 \pm 0.5(2.33)$ & 0.11 \\
Diameter stenosis (\%) & $25 \pm 11(21.5)$ & $23 \pm 10(21)$ & 0.43 \\
In-stent late loss (mm) & $0.54 \pm 0.39(0.50)$ & $0.59 \pm 0.22(0.58)$ & 0.25 \\
\hline
\end{tabular}

Data given as mean \pm SD (median).

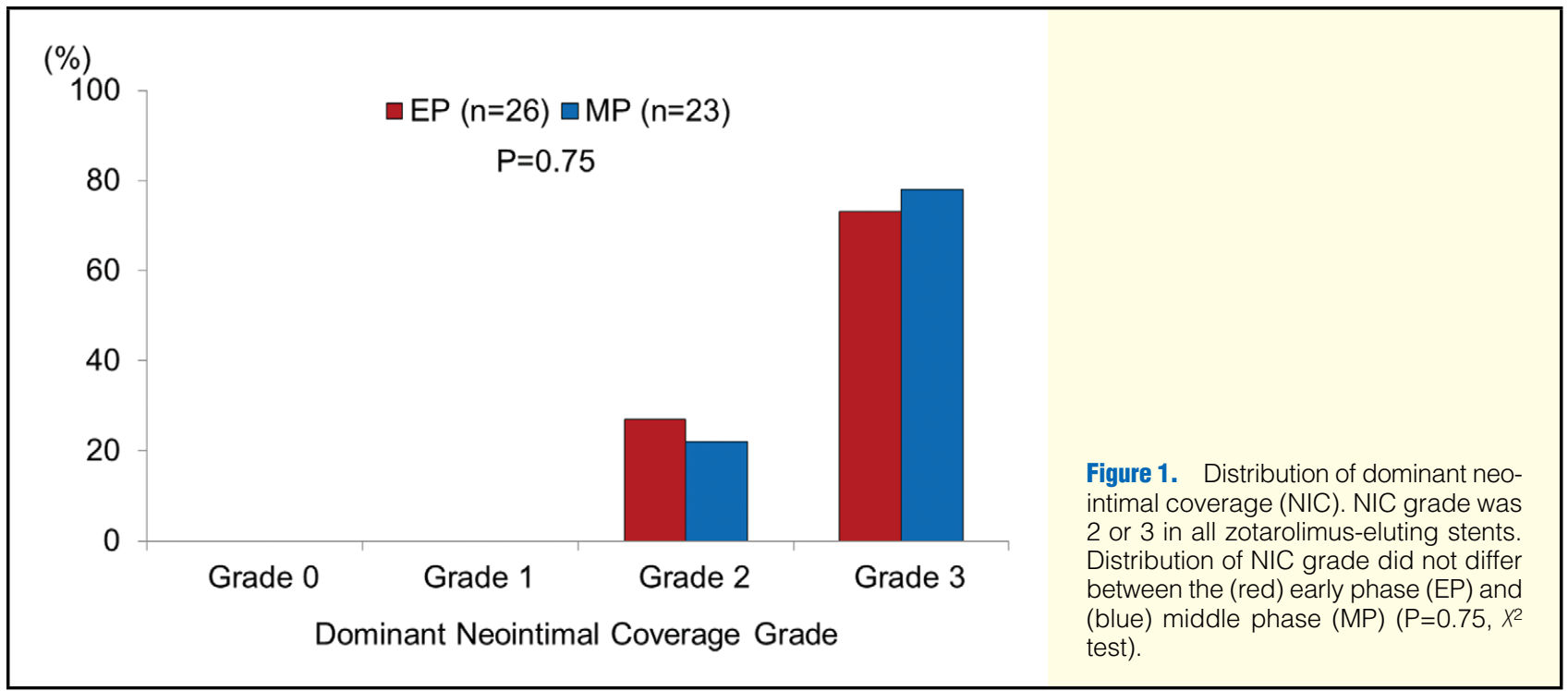

\section{Statistical Analysis}

All results are expressed as mean \pm SD (median) unless otherwise stated. Groups were compared using the Wilcoxon rank sum test. Categorical variables were analyzed with Fisher's exact test for $2 \times 2$ comparisons; the chi-square test was used for more than $2 \times 2$ comparisons. Statistical significance was defined as $\mathrm{P}<0.05$. All calculations were performed using JMP 8.0 (SAS Institute, Cary, NC, USA).

\section{Results}

\section{Patients}

Patient characteristics were equally distributed between the EP and MP groups (Table 1). Lesion and procedural characteristics are given in Table 2. In terms of lesion characteristics, distribution of the target vessel differed between the 2 groups $(\mathrm{P}=0.036)$. There were no differences in procedural characteristics between the groups.

\section{QCA}

The QCA findings are listed in Table 3. The data showed no statistical differences between the EP and MP groups at pre- intervention assessment. Minimum lumen diameter tended to be smaller in the EP group at post-intervention assessment, but not significantly so. At follow-up, there were no significant differences between the groups. There was little difference in in-stent late loss from before intervention to follow-up between the EP and MP groups $(0.54 \pm 0.39 \mathrm{~mm}$ vs. $0.59 \pm 0.22 \mathrm{~mm}$, $\mathrm{P}=0.25)$.

\section{Angioscopic Findings}

Dominant NIC grade was either grade 2 or grade 3 in all stents and did not significantly differ between the groups (Figure 1). A representative case is shown in Figure 2. There was a trend toward more heterogeneous NIC in the EP group (Figure 3, $\mathrm{P}=0.070)$. Stent exposure grade was significantly different between the 2 groups ( $\mathrm{P}=0.026$, Figure 4$)$; the majority of stents were exp 0 in the MP group, whereas stents in the EP group were distributed from exp 0 to $\exp 3$. Nonetheless, widely exposed struts ( $\geq \exp 3)$ were rarely observed in either the EP $(8 \%)$ or MP $(0 \% ; \mathrm{P}=0.49)$ group. Existence of thrombus and YP is shown in Figure 5. All the thrombi detected on angioscopy were mural, subclinical, red, and associated with a site of NIC grade 0 or 1 . Thrombus was found in 6 patients (23\%) 


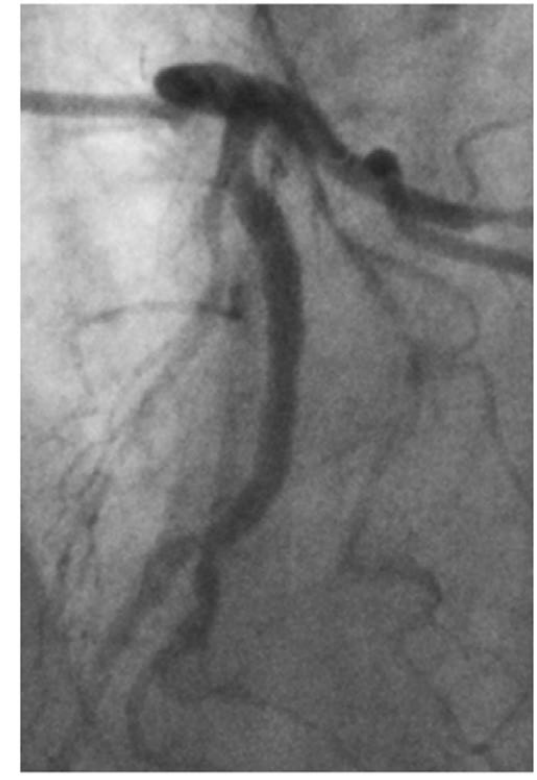

Final image of initial procedure

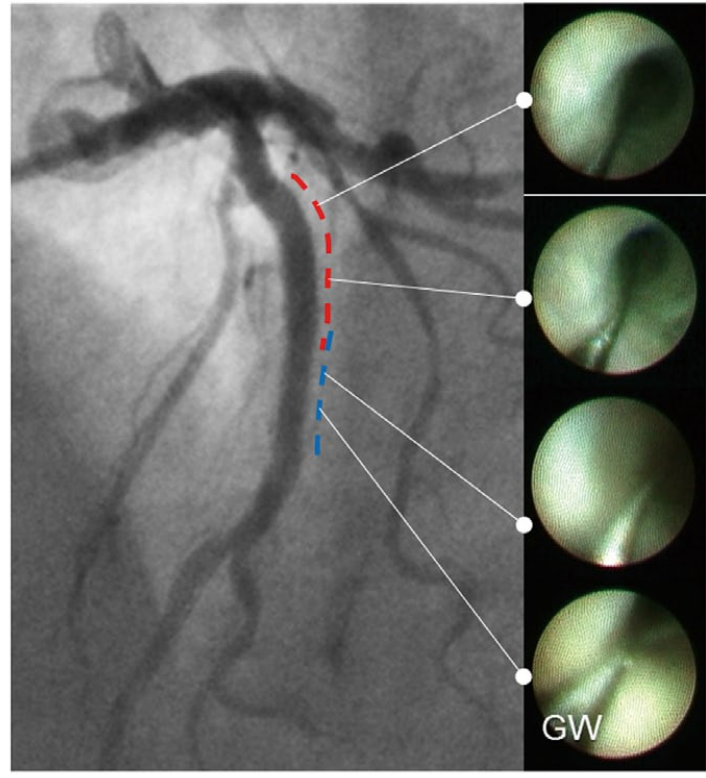

Four months after ZES implantation

Figure 2. Representative case. Angiograms at follow-up showed no restenosis at the site of 2 zotarolimus-eluting stents (ZES; proximal segment, $3.5 \times 18 \mathrm{~mm}$; distal segment, $3.5 \times 15 \mathrm{~mm}$ ). Angioscopy of the ZES implanted in the proximal segment showed homogeneous neointimal coverage (NIC) grade 2 without thrombi. In contrast, images of the ZES implanted in the distal segment showed homogeneous NIC grade 3 without thrombi. Dotted red line, ZES $(3.5 \times 18 \mathrm{~mm})$-implanted site; dotted blue line, ZES $(3.5 \times 15 \mathrm{~mm})$-implanted site. GW, guidewire.

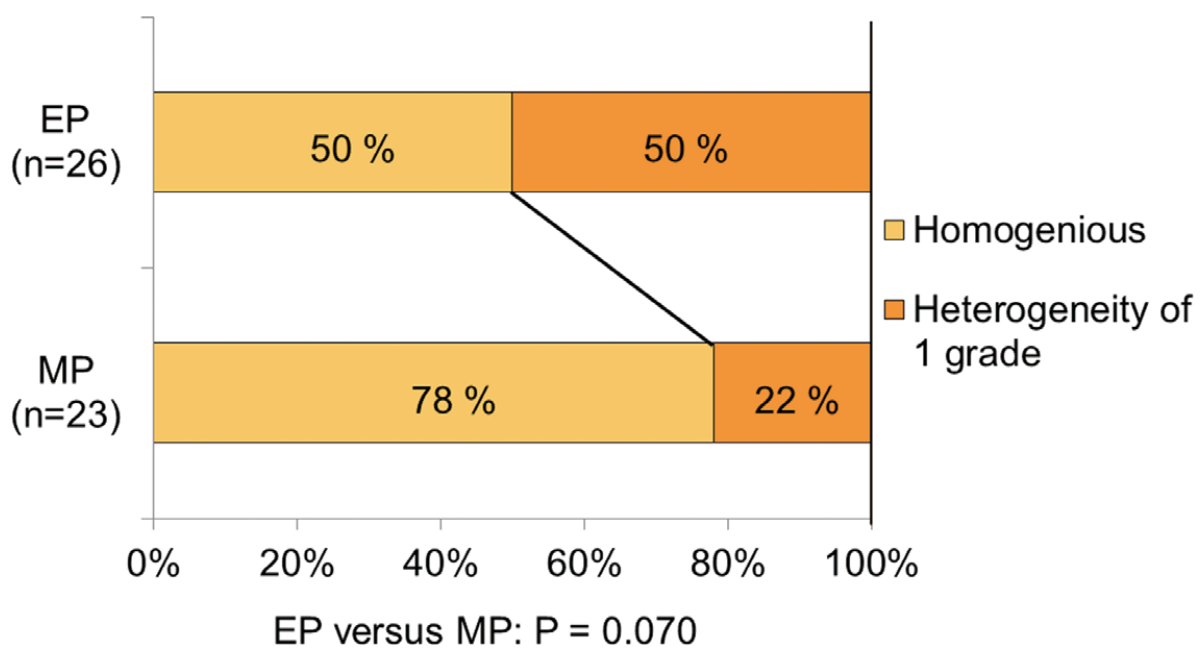

Figure 3. Heterogeneity of neointimal coverage (NIC) grade. Fifty percent of zotarolimus-eluting stents (ZES) had homogenous NIC. The remaining stents showed heterogeneity of 1 grade in the early phase (EP) group. Seventy-eight percent of ZES had homogenous NIC in the middle phase (MP). EP vs. MP, $P=0.070$ ( $X^{2}$ test).

in the EP group and in only 1 patient (4\%) in the MP group, although the difference did not reach statistical significance. YP were more frequently observed in the EP group (58\%) than in the MP group $(13 \% ; \mathrm{P}=0.0025)$.

\section{Discussion}

The main findings of this study were 3 -fold. First, dominant NIC grade ranged from grade 2 to grade 3 in all ZES, and distribution of the dominant NIC grade did not differ between the 


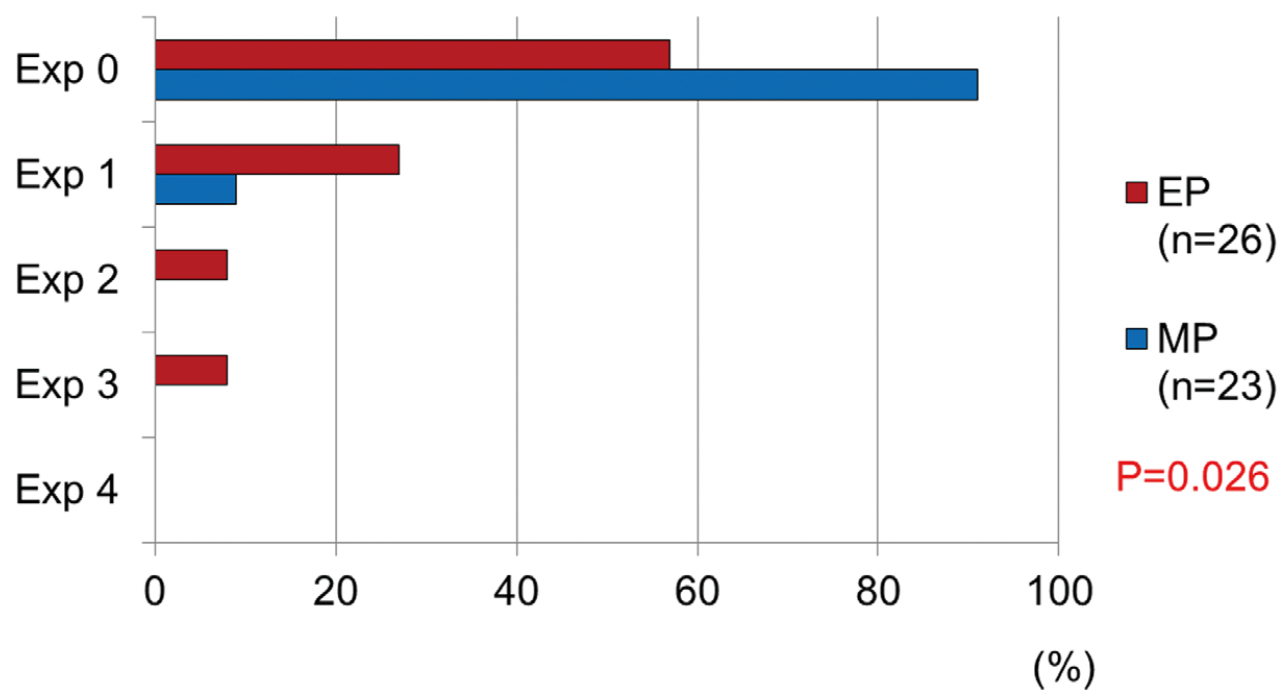

Figure 4. Distribution of strut exposure. In $91 \%$ of the zotarolimus-eluting stents, exposure of the struts was scored as exp 0 in the (blue) middle phase (MP), but ranged between exp 0 and exp 3 in the (red) early phase (EP), indicating a significant difference between the EP and MP groups ( $P=0.026, X^{2}$ test).

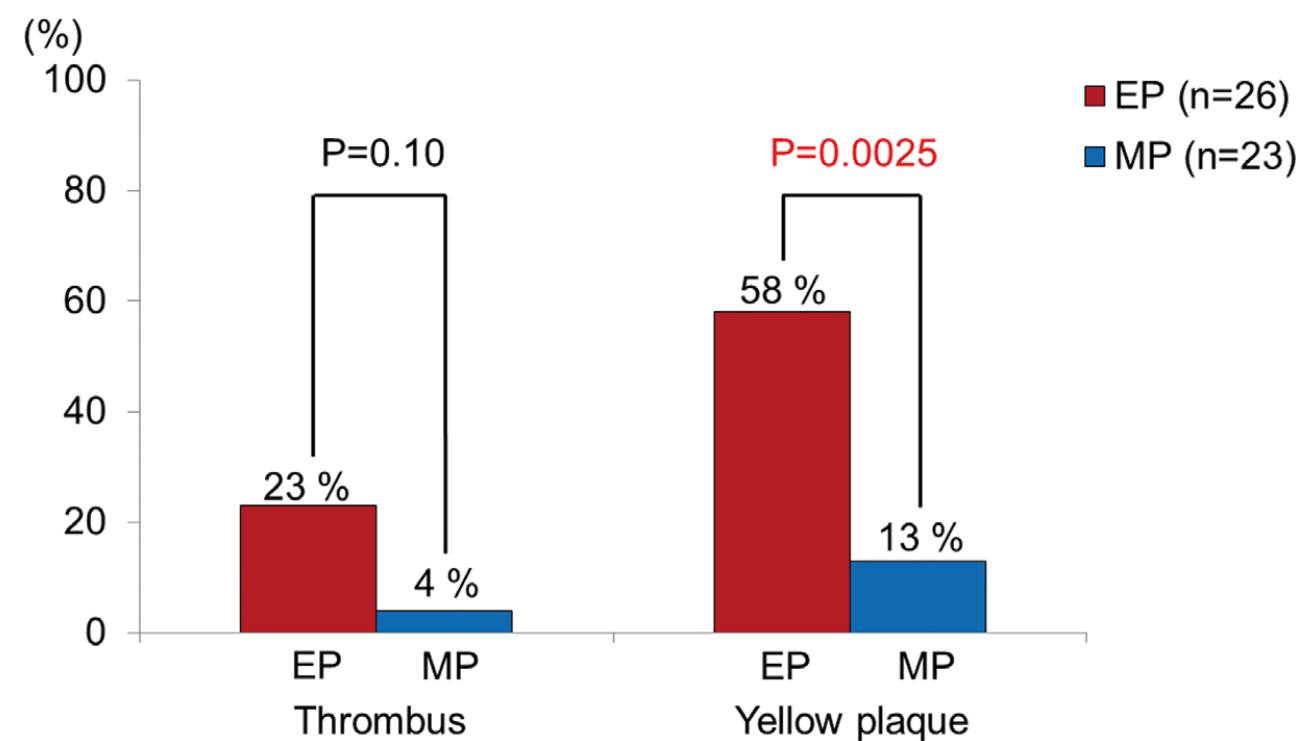

Figure 5. Frequency of thrombus and yellow plaque. Thrombus was detected in $23 \%$ of zotarolimus-eluting stents (ZES) in the (red) early phase (EP) and in $4 \%$ in the (blue) middle phase (MP; EP vs. MP, $P=0.10, X^{2}$ test). Yellow plaque was observed in $58 \%$ of ZES in EP and in $13 \%$ in MP (EP vs. MP, $P=0.0025, X^{2}$ test).

EP and MP groups. Second, widely exposed struts ( $\geq \exp 3)$ were rarely observed in either group. Last, YP were more frequently observed in the EP group.

Using angioscopy, we previously found that after sirolimuseluting stent (SES; Cypher, Cordis, Miami, FL, USA) implantation the dominant NIC grade tended to be grade 1 at 3-24 months. ${ }^{9,11,12}$ In contrast, Kim et al reported that on optical coherence tomography (OCT), $99.9 \%$ of the stent struts were covered by neointima at least 3 months after ZES implantation. ${ }^{25}$ Although the present methodology differed from these 2 studies, NIC following ZES implantation was similar in the present study. Although there are no reports on the relationship between neointimal thickness and re-endothelialization as determined with OCT, previous angioscopic studies have found no thrombus adhesion at the site of NIC grade 2 or 3 , suggesting that re-endothelialization was adequate at these 
sites. ${ }^{9,11,13}$ In contrast to SES, arterial repair may have substantially been achieved as early as 4 months after ZES implantation because dominant NIC grade ranged from grade 2 to 3 .

Subclinical thrombus was detected in $23 \%$ of stents in EP, and in only $4 \%$ in MP. According to the pathological report, thrombus adhesion to the vessel wall/stent strut was an initial phase of neointimal formation. ${ }^{26,27} \mathrm{ZES}$ in the EP is thought to be still in the process of arterial repair because it had the higher tendency of thrombus adhesion than ZES in the MP.

Angioscopically detected YP is considered to be a vulnerable plaque based on the following observations: in one study, angioscopy and OCT showed that as the fibrous cap became thinner, the yellow tone of the plaque became more intense and as the cap became thicker, the color of the plaque tended to whiten; ${ }^{16,17}$ in another study OCT also showed that patients with a thin fibrous cap were prone to acute coronary syndrome (ACS);28 and plaque ruptures were angioscopically detected within YP in patients with ACS. ${ }^{18}$ In contrast, angioscopy showed that YP was covered by white neointima 6 months after bare-metal stent implantation. ${ }^{7,15}$ Although the present patients had stable angina pectoris, given the trend toward heterogeneity 4 months after ZES implantation in the present study, NIC over YP had not been completed by that time and arterial repair was still ongoing.

\section{Clinical Implications}

It is currently recommended that DAPT be continued for at least 1 year after DES implantation, ${ }^{4}$ but DAPT can cause severe side-effects in some patients. Severe bleeding events occurred in $3.0 \%$ of patients who had undergone percutaneous coronary intervention within 1 year after stenting. ${ }^{29}$ In addition, the bleeding event rate has been reported to be higher in patients on the triple anti-thrombotic therapy of aspirin, clopidogrel, and warfarin than in those without warfarin, and DES implantation is sometimes necessary in patients who have already been on warfarin..$^{30,31}$ Tolerance to DAPT must also be considered. Even with clopidogrel, $4.6 \%$ of patients had to discontinue DAPT within 1 month due to several side-effects in addition to bleeding complication. ${ }^{32}$ Accidental premature discontinuation of anti-platelet drugs is also considered to be a high risk for LST. ${ }^{33,34}$ Under these circumstances, after DES implantation it is favorable to switch from DAPT to monoantiplatelet therapy as soon as arterial healing is complete.

In our previous angioscopy studies the dominant NIC grade tended to be grade 1 at 3-24 months after SES implantation, which suggests incomplete re-endothelialization..$^{9,11,13}$ Observational studies, however, have found no increase in adverse events even when DAPT was switched to monotherapy 6 or 12 months after stenting with SES. ${ }^{35,36}$ Taking these findings together, mono-antiplatelet therapy may be sufficient to prevent stent thrombosis in DES with dominant NIC grade $\geq 1$ even if re-endothelialization is incomplete. In the present study, the dominant NIC grade of all ZES was grade 2 or 3 as early as 4 months after implantation although some of the stents were grade 1 due to heterogeneity. It appears then that the risk of stent thrombosis may be low even if NIC grade 1 is partly present.

Pathology showed that when the ratio of uncovered struts to total stent struts per section was $>30 \%$, this was a risk factor for stent thrombosis. ${ }^{37}$ In the present study, only $8 \%$ of the stents had such a ratio in EP. Accordingly, although multiple factors are associated with stent thrombosis, the risk of stent thrombosis at 4 months after ZES implantation might be low even if DAPT is switched to mono-antiplatelet therapy. ${ }^{38}$

\section{Study Limitations}

This study has several important limitations. First, angioscopy was not performed serially in the same patients after stent implantation, although the patient characteristics did not differ significantly between the EP and MP groups. Second, distribution of the target vessel was significantly different between the groups. Nonetheless, the difference may have little impact on NIC because QCA data, stent size, and stent length were not different between the groups. Third, although serial angioscopy observations are necessary to evaluate the chronological changes in the plaque color, it is impossible because we have no angioscopic data relating to immediately after the stent implantation. Fourth, although we explored intra-stent surfaces of Endeavor ZES, a new version of the ZES (Resolute Integrity ZES; Medtronic), is now available in the clinical setting. We cannot directly extrapolate the present results to the new ZES. Fifth, although angioscopy provides a wide-angle view, anatomical structures, such as tortuous vessels, may disturb the complete circumferential view, which may lead to the missing of small regions. Angioscopic evaluation of NIC on the stent surface remains qualitative. Nonetheless, angioscopy is a robust tool to detect the thrombus. Finally, this study involved a single-center, small sample, and carried out non-randomized observation of intrastent surfaces by angioscopy. In order to elucidate the optimal duration of DAPT, a large-scale, randomized control study is warranted. Analysis across 5 registration trials showed that ZES with DAPT over 6 months did not increase clinical events including stent thrombosis in comparison with DAPT over $\geq 12$ months. Recently, the RESET study verified our hypothesis. ${ }^{39}$

\section{Conclusions}

Although ZES-implanted lesions were still in the process of arterial repair at 4 months after stenting, the majority of the struts were covered by the neointima; exposed struts as well as thrombus adhesion were rarely observed at this time. Sufficient arterial repair may have occurred by 4 months after ZES stenting.

\section{Acknowledgments}

We acknowledge the expertise of Drs Shin Okamoto, Nobuaki Tanaka, Tomoharu Dohi, Kei Sato, Tsuyoshi Mishima, Kiyonori Nanto, Yukika Mizukami, Takuma Iida, Takashi Kanda, and Tatsuya Shiraki in performing cardiac catheterization.

\section{Disclosures}

Conflict of Interest Statement: The authors have no conflict of interest to declare. Name of Grant: None.

\section{References}

1. Moses JW, Leon MB, Popma JJ, Fitzgerald PJ, Holmes DR, O'Shaughnessy C, et al. Sirolimus-eluting stents versus standard stents in patients with stenosis in a native coronary artery. $N$ Engl J Med 2003; 349: 1315-1323.

2. Stone GW, Moses JW, Ellis SG, Schofer J, Dawkins KD, Morice MC, et al. Safety and efficacy of sirolimus- and paclitaxel-eluting coronary stents. N Engl J Med 2007; 356: $998-1008$.

3. Spaulding C, Daemen J, Boersma E, Cutlip DE, Serruys PW. A pooled analysis of data comparing sirolimus-eluting stents with bare-metal stents. N Engl J Med 2007; 356: 989-997.

4. Levine GN, Bates ER, Blankenship JC, Bailey SR, Bittl JA, Cercek B, et al. 2011 ACCF/AHA/SCAI Guideline for Percutaneous Coronary Intervention: Executive summary: A report of the American College of Cardiology Foundation/American Heart Association Task Force on Practice Guidelines and the Society for Cardiovascular Angiography and Interventions. Circulation 2011; 124: 2574-2609.

5. Kandzari DE, Leon MB, Popma JJ, Fitzgerald PJ, O'Shaughnessy C, 
Ball MW, et al. Comparison of zotarolimus-eluting and sirolimuseluting stents in patients with native coronary artery disease: A randomized controlled trial. J Am Coll Cardiol 2006; 48: 2440-2447.

6. Leon MB, Mauri L, Popma JJ, Cutlip DE, Nikolsky E, O'Shaughnessy $\mathrm{C}$, et al. A randomized comparison of the ENDEAVOR zotarolimuseluting stent versus the TAXUS paclitaxel-eluting stent in de novo native coronary lesions 12-month outcomes from the ENDEAVOR IV trial. J Am Coll Cardiol 2010; 55: 543-554.

7. Sakai S, Mizuno K, Yokoyama S, Tanabe J, Shinada T, Seimiya K, et al. Morphologic changes in infarct-related plaque after coronary stent placement: A serial angioscopy study. J Am Coll Cardiol 2003; 42: $1558-1565$.

8. Mizuno K, Arai T, Satomura K, Shibuya T, Arakawa K, Okamoto Y, et al. New percutaneous transluminal coronary angioscope. J Am Coll Cardiol 1989; 13: 363-368.

9. Awata M, Nanto S, Uematsu M, Morozumi T, Watanabe T, Onishi T, et al. Angioscopic comparison of neointimal coverage between zotarolimus- and sirolimus-eluting stents. J Am Coll Cardiol 2008; 52: 789-790.

10. Takano M, Mizuno K, Yokoyama S, Seimiya K, Ishibashi F, Okamatsu $\mathrm{K}$, et al. Changes in coronary plaque color and morphology by lipidlowering therapy with atorvastatin: Serial evaluation by coronary angioscopy. J Am Coll Cardiol 2003; 42: 680-686.

11. Awata M, Kotani J, Uematsu M, Morozumi T, Watanabe T, Onishi T, et al. Serial angioscopic evidence of incomplete neointimal coverage after sirolimus-eluting stent implantation: Comparison with baremetal stents. Circulation 2007; 116: 910-916.

12. Kotani J, Awata M, Nanto S, Uematsu M, Oshima F, Minamiguchi H, et al. Incomplete neointimal coverage of sirolimus-eluting stents: Angioscopic findings. J Am Coll Cardiol 2006; 47: 2108-2111.

13. Awata M, Nanto S, Uematsu M, Morozumi T, Watanabe T, Onishi T, et al. Heterogeneous arterial healing in patients following paclitaxeleluting stent implantation: Comparison with sirolimus-eluting stents. JACC Cardiovasc Interv 2009; 2: 453-458.

14. den Heijer P, Foley DP, Hillege HL, Lablanche JM, van Dijk RB, Franzen D, et al; European Working Group on Coronary Angioscopy. The 'Ermenonville' classification of observations at coronary angioscopy: Evaluation of intra- and inter-observer agreement: European Working Group on Coronary Angioscopy. Eur Heart J 1994; 15: $815-822$.

15. Ueda Y, Asakura M, Yamaguchi O, Hirayama A, Hori M, Kodama K. The healing process of infarct-related plaques: Insights from 18 months of serial angioscopic follow-up. J Am Coll Cardiol 2001; 38: 19161922.

16. Takano M, Jang IK, Inami S, Yamamoto M, Murakami D, Okamatsu $\mathrm{K}$, et al. In vivo comparison of optical coherence tomography and angioscopy for the evaluation of coronary plaque characteristics. Am J Cardiol 2008; 101: 471-476.

17. Kubo T, Imanishi T, Takarada S, Kuroi A, Ueno S, Yamano T, et al. Implication of plaque color classification for assessing plaque vulnerability: A coronary angioscopy and optical coherence tomography investigation. JACC Cardiovasc Interv 2008; 1: 74-80.

18. Ueda Y, Asakura M, Hirayama A, Komamura K, Hori M, Komada K. Intracoronary morphology of culprit lesions after reperfusion in acute myocardial infarction: Serial angioscopic observations. J Am Coll Cardiol 1996; 27: 606-610.

19. Kodama K, Komatsu S, Ueda Y, Takayama T, Yajima J, Nanto S, et al. Stabilization and regression of coronary plaques treated with pitavastatin proven by angioscopy and intravascular ultrasound. Circ J 2010; 74: 1922-1928.

20. Hirayama A, Saito S, Ueda Y, Takayama T, Honye J, Komatsu S, et al. Quantitative changes in coronary plaque associated with atorvastatin therapy. Circ J 2009; 73: 718-725.

21. Awata M, Uematsu M, Sera F, Ishihara T, Watanabe T, Fujita M, et al. Angioscopic assessment of arterial repair following biodegradable polymer-coated biolimus A9-eluting stent implantation: Comparison with durable polymer-coated sirolimus-eluting stent. Circ J 2011; 75: $1113-1119$.

22. Tajika K, Okamatsu K, Takano M, Inami S, Yamamoto M, Murakami $\mathrm{D}$, et al. Malondialdehyde-modified low-density lipoprotein is a use- ful marker to identify patients with vulnerable plaque. Circ J 2012; 76: $2211-2217$.

23. Kashiyama T, Ueda Y, Nemoto T, Wada M, Masumura Y, Matsuo K, et al. Relationship between coronary plaque vulnerability and serum n-3/n-6 polyunsaturated fatty acid ratio. Circ J 2011; 75: 2432-2438.

24. Haase J, Escaned J, van Swijndregt EM, Ozaki Y, Gronenschild E, Slager CJ, et al. Experimental validation of geometric and densitometric coronary measurements on the new generation Cardiovascular Angiography Analysis System (CAAS II). Cathet Cardiovasc Diagn 1993; 30: 104-114.

25. Kim JS, Jang IK, Fan C, Kim TH, Park SM, Choi EY, et al. Evaluation in 3 months duration of neointimal coverage after zotarolimuseluting stent implantation by optical coherence tomography: The ENDEAVOR OCT trial. JACC Cardiovasc Interv 2009; 2: $1240-$ 1247.

26. Schwartz RS. Pathophysiology of restenosis: Interaction of thrombosis, hyperplasia, and/or remodeling. Am J Cardiol 1998; 9: 14E17E.

27. Nikol S, Huehns TY, Höfling B. Molecular biology and post-angioplasty restenosis. Atherosclerosis 1996; 123: 17-31.

28. Tanaka A, Imanishi T, Kitabata H, Kubo T, Takarada S, Tanimoto T, et al. Morphology of exertion-triggered plaque rupture in patients with acute coronary syndrome: An optical coherence tomography study. Circulation 2008; 118: 2368-2373.

29. To AC, Armstrong G, Zeng I, Webster MW. Noncardiac surgery and bleeding after percutaneous coronary intervention. Circ Cardiovasc Interv 2009; 2: 213-221.

30. Sorensen R, Hansen ML, Abildstrom SZ, Hvelplund A, Andersson C, Jorgensen C, et al. Risk of bleeding in patients with acute myocardial infarction treated with different combinations of aspirin, clopidogrel, and vitamin K antagonists in Denmark: A retrospective analysis of nationwide registry data. Lancet 2009; 374: 1967-1974.

31. Toyoda K, Yasaka M, Iwade K, Nagata K, Koretsune Y, Sakamoto T, et al. Dual antithrombotic therapy increases severe bleeding events in patients with stroke and cardiovascular disease: A prospective, multicenter, observational study. Stroke 2008; 39: 1740-1745.

32. Bertrand ME, Rupprecht HJ, Urban P, Gershlick AH. Double-blind study of the safety of clopidogrel with and without a loading dose in combination with aspirin compared with ticlopidine in combination with aspirin after coronary stenting: The CLopidogrel ASpirin Stent International Cooperative Study (CLASSICS). Circulation 2000; 102: $624-629$.

33. Ge L, Airoldi F, Iakovou I, Cosgrave J, Michev I, Sangiorgi GM, et al. Clinical and angiographic outcome after implantation of drug-eluting stents in bifurcation lesions with the crush stent technique: Importance of final kissing balloon post-dilation. J Am Coll Cardiol 2005; 46: $613-620$.

34. Kuchulakanti PK, Chu WW, Torguson R, Ohlmann P, Rha SW, Clavijo LC, et al. Correlates and long-term outcomes of angiographically proven stent thrombosis with sirolimus- and paclitaxel-eluting stents. Circulation 2006; 113: 1108-1113.

35. Kimura T, Morimoto T, Nakagawa Y, Tamura T, Kadota K, Yasumoto $\mathrm{H}$, et al. Antiplatelet therapy and stent thrombosis after sirolimuseluting stent implantation. Circulation 2009; 119: 987-995.

36. Park SJ, Park DW, Kim YH, Kang SJ, Lee SW, Lee CW, et al. Duration of dual antiplatelet therapy after implantation of drug-eluting stents. N Engl J Med 2010; 362: 1374-1382.

37. Finn AV, Joner M, Nakazawa G, Kolodgie F, Newell J, John MC, et al. Pathological correlates of late drug-eluting stent thrombosis: Strut coverage as a marker of endothelialization. Circulation 2007; 115: $2435-2441$.

38. Cutlip DE, Windecker S, Mehran R, Boam A, Cohen DJ, van Es GA, et al; Academic Research Consortium. Clinical end points in coronary stent trials: A case for standardized definitions. Circulation 2007; 115: $2344-2351$.

39. Kim BK, Hong MK, Shin DH, Nam CM, Kim JS, Ko YG, et al; RESET Investigators. A new strategy for discontinuation of dual antiplatelet therapy: The RESET Trial (REal Safety and Efficacy of 3-month dual antiplatelet Therapy following Endeavor zotarolimuseluting stent implantation). J Am Coll Cardiol 2012; 60: 1340-1348. 